Archive for

Organic Chemistry

Arkivoc 2017, part ii, 433-445

\title{
Synthesis of new zinc(II) phthalocyanine conjugates with block copolymers for cancer therapy
}

\author{
Łukasz Lamch, ${ }^{\text {a }}$ Marta Tsirigotis-Maniecka, ${ }^{\text {a Julita Kulbacka, }}{ }^{\mathrm{b}}$ Kazimiera A. Wilk ${ }^{\mathrm{a} *}$ \\ a Department of Organic and Pharmaceutical Technology, Faculty of Chemistry,
} Wroclaw University of Science and Technology, Wybrzeze Wyspianskiego 27, 50-370 Wroclaw, Poland

${ }^{b}$ Department of Medical Biochemistry, Medical University of Wrocław, Chałubińskiego 10, 50-368 Wrocław, Poland

E-mail: kazimiera.wilk@pwr.edu.pl

\section{Dedicated to Prof. Jacek Młochowski on the occasion of his $80^{\text {th }}$ anniversary}

Received 06-27-2016

Accepted 10-23-2016

Published on line 12-14-2016

\begin{abstract}
Synthetic routes towards new conjugates of hydrophilic zinc(II) phthalocyanine (ZnPc) with poly(ethylene oxide)-b-poly(propylene oxide)-b-poly(ethylene oxide) (Pluronic P123) and poly(L-lactide) (PLLA), are described. The main semiproduct ZnPc was obtained by heating 4-nitrophthalimide with urea and zinc chloride, followed by the reduction step. Steglich esterification was used to synthesize two ZnPc-conjugated block copolymers, further utilized in fabrication of polymeric micelles (PMs) - functionalized with the zinc(II) phthalocyanine-type moiety. Biological evaluation of the PMs indicated an acceptable biocompatibility level in accord with requirements in the field of nanotheranostics and nanomedicine.
\end{abstract}

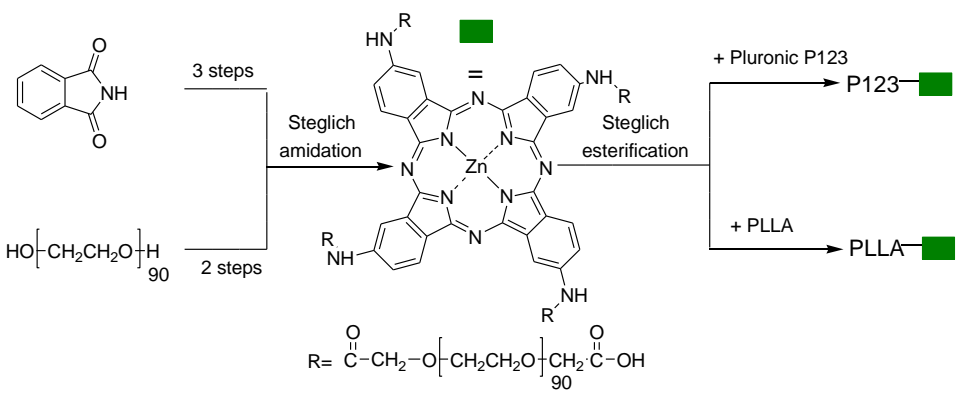

Keywords: ZnPc-conjugated block copolymers; cyclotetramerization; Steglich esterification; fluorescent polymeric micelles; diagnostic marker; in vitro biological evaluation 


\section{Introduction}

One of the most interesting groups of porphyrin-like compounds, considering physicochemical properties, are the zinc(II) phthalocyanines - light-sensitive molecules, known for their exceptional stability and light absorption properties in the red/near IR region ( $\varepsilon$ may exceed $10^{5} \mathrm{M}^{-1} \mathrm{~cm}^{-1}$ for the $Q$ band, often located at 650-700 nm). ${ }^{1}$ These compounds comprise not only a variety of components of biosensors in imaging bioapplications, but also are one of the most promising second generation photosensitizers for photodynamic therapy of cancers. ${ }^{2-4}$ Moreover, phthalocyanines exhibit a high fluorescence quantum yield and their physical and photochemical properties can be easily modified by exchange of peripheral groups. ${ }^{5}$

The principal limitation of most of the zinc(II) phthalocyanine-type derivatives, used as photosensitizers or fluorescent markers, is their low solubility, even in organic solvents, their instability, and tendency to aggregate in water solutions, which severely limits their potential application in the physiological environment. $^{6}$ To overcome these drawbacks, hydrophilic groups such as sulfonate, ${ }^{7,8}$ phosphonate, ${ }^{9}$ saccharide, ${ }^{10}$ carboxylate $^{10-12}$ or tertiary amine ${ }^{13-15}$ groups can be introduced into the molecules. Unfortunately, those zinc(II) phthalocyanine derivatives may aggregate in aqueous systems, resulting in loss of absorbance, fluorescence and photoactivity. ${ }^{16}$ That is why the present study has been focused on the synthesis and characterization of poly(ethylene oxide)-modified zinc(II) phthalocyanine, a nonionic and watersoluble compound, with its application as a fluorescent marker for cancer therapy.

Generally, the synthesis of substituted phthalocyanines is a multistep process, including preparation of the appropriate phthalimide or phthalonitrile derivative, their further high-temperature condensation (cyclotetramerization) to obtain the phthalocyanine ring and eventually peripheral group exchange, if needed. Amino-substituted phthalocyanines cannot be synthesized by self-condensation of substrates containing amino groups, due to interference by the amino groups in the cyclotetramerization process. ${ }^{17}$ To solve this problem, two synthetic routes are usually employed. One approach is that tetranitrophthalocyanines are prepared in the first step, followed by reduction to amino-derivatives. The other is that the amino group in the phthalonitrile or phthalimide derivative is protected by acyl or tosyl groups before the substrate is cyclotetramerized, the product then hydrolyzed to the tetraaminophthalocyanine. The first method needs relatively fewer reaction steps, so is usually preferred. ${ }^{18}$

A convenient starting material for zinc phthalocyanine possessing peripheral amine groups is zinc tetranitrophthalocyanine, obtained upon heating 4-nitrophthalimide with an appropriate catalyst, metal salt (e.g. zinc chloride or acetate) and urea. The latter derivative can be easily reduced to zinc tetraaminophthalocyanine utilizing sodium sulfide ${ }^{18}$ or hydrazine. ${ }^{17}$ An additional advantage of this procedure is that 4-nitrophthalimide is conveniently prepared by nitration of phthalimide. ${ }^{19}$

Poly(ethylene oxide), a nonionic compound commonly used to enhance water solubility or dispersability of many substances, can be attached to zinc tetraaminophthalocyanine by two approaches: zinc tetraaminophthalocyanine transformation to zinc tetra( $\mathrm{N}$-carbonylacrylic)aminophthalocyanine utilizing reaction with maleic anhydride, ${ }^{18}$ followed by coupling with poly(ethylene glycol) or synthesis of carboxyl group terminated poly(ethylene glycol) that can react directly with zinc tetraaminophthalocyanine. Both synthetic routes can be conducted utilizing Steglich esterification or its amide modification - a general method of preparation of labile esters or amides under very mild conditions. ${ }^{20}$ By this approach it is also possible to avoid product degradation in the ZnPc-conjugated block copolymers.

To overcome the poor solubility, target specificity and difficulties in tracking of anticancer compounds in tissue systems, many carriers, such as oil-core polyelectrolyte nanocarriers, solid lipid nanoparticles, polymer 
conjugates, polymeric nanoparticles and micelles, have been developed. ${ }^{21-25}$ Polymeric micelles are nanoscopic structures (hydrodynamic diameter is often below $100 \mathrm{~nm}$ ) generated by the self-assembly of amphiphilic block copolymers in water in a concentration exceeding the critical micelle concentration. Such structures have attracted much attention as nanocarriers of anticancer drugs due to the possibility of modifying their hydrophilic corona with ligands or fluorescence markers. ${ }^{5}$

In order to evaluate application properties of $\mathrm{ZnPc}$ as a fluorescent agent, we have synthesized new conjugates with two block copolymers, which were further utilized to prepare functionalized polymeric micelles and characterized by physical and biological methods. Polymeric nanostructures, in the form of the above-mentioned micelles, have attracted our attention as delivery vehicles in cancer therapy and diagnostics, due to their ability to selectively accumulate within the tumor tissue with vestigial or no uptake by non-target cells without the loss of their activity. Thus, the ZnPc-functionalized polymeric micelles may constitute a promising addition to the inventory of nanotheranostics and to monitor the efficiency of chemotherapy.

\section{Results and Discussion}

\section{Synthetic studies}

In order to prepare a water soluble zinc(II) phthalocyanine ( $\mathrm{ZnPc})$, the most appropriate starting materials were compounds which it was possible to synthesize in convenient reactions: carboxyl group terminated poly(ethylene glycol) $\mathbf{1}$ and 4-nitrophthalimide 2, as well as commercially available urea and zinc chloride hexahydrate. The carboxyl group terminated poly(ethylene glycol) $\mathbf{1}$ was synthesized in a multistep reaction as outlined in Scheme 1, starting from commercially available dihydroxy-terminated poly(ethylene oxide). The resulting compound 1 analyses performed by ${ }^{1} \mathrm{H}$ NMR and FT-IR spectroscopies were in a good agreement with the structurally similar compounds obtained from slightly different methods by Niculescu-Duvaz et al. ${ }^{26}$ 4-Nitrophthalimide $\mathbf{2}$ was synthesized by standard, low temperature nitration, starting from the readilyavailable phthalimide (Scheme 2). After recrystallization, the purity and identity of the compound $\mathbf{2}$ was confirmed by a very sharp melting point $\left(194.5-195{ }^{\circ} \mathrm{C}\right)$ and ${ }^{1} \mathrm{H}$ NMR spectroscopy, fully consistent with literature data. ${ }^{27}$ The yield obtained of compound 2 was only slightly lower than that reported by Young et al. (61\% in comparison to $70 \%){ }^{27}$

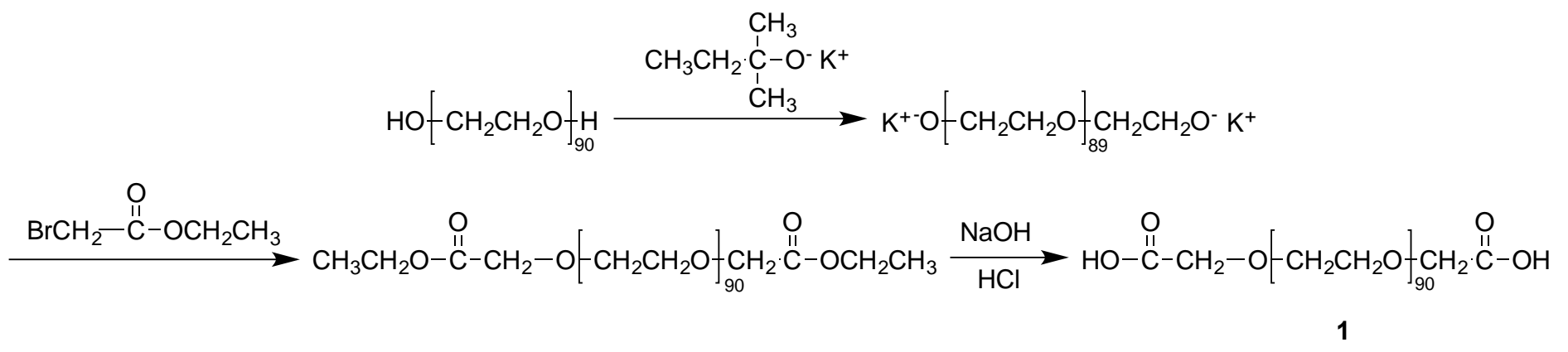

Scheme 1. Synthesis of carboxyl terminated poly(ethylene glycol) 1. 


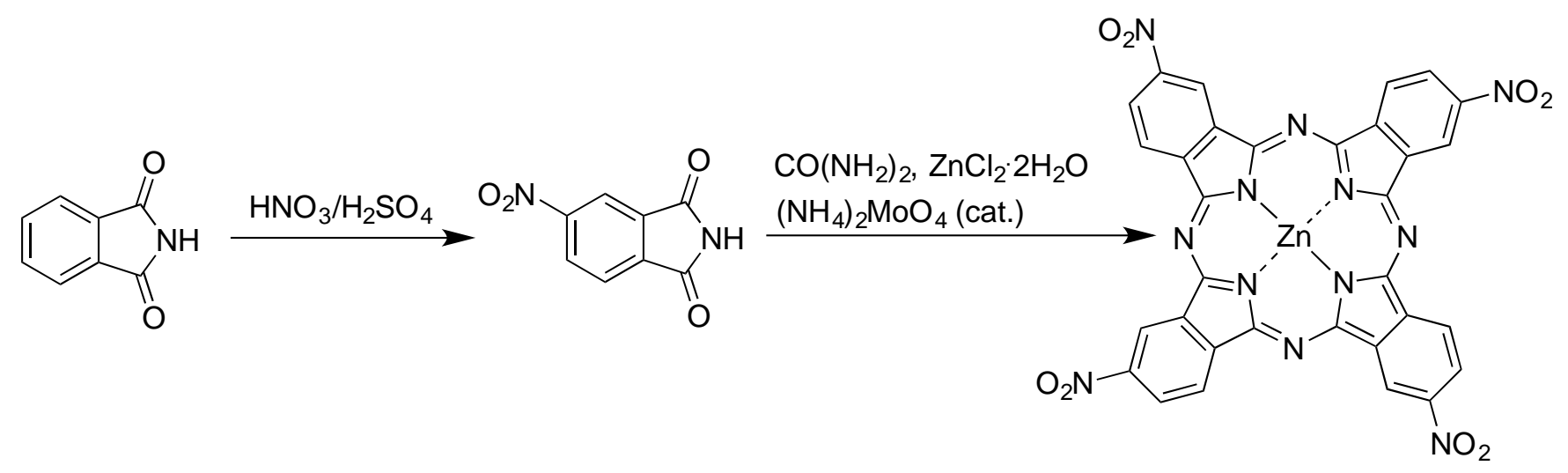

2

3

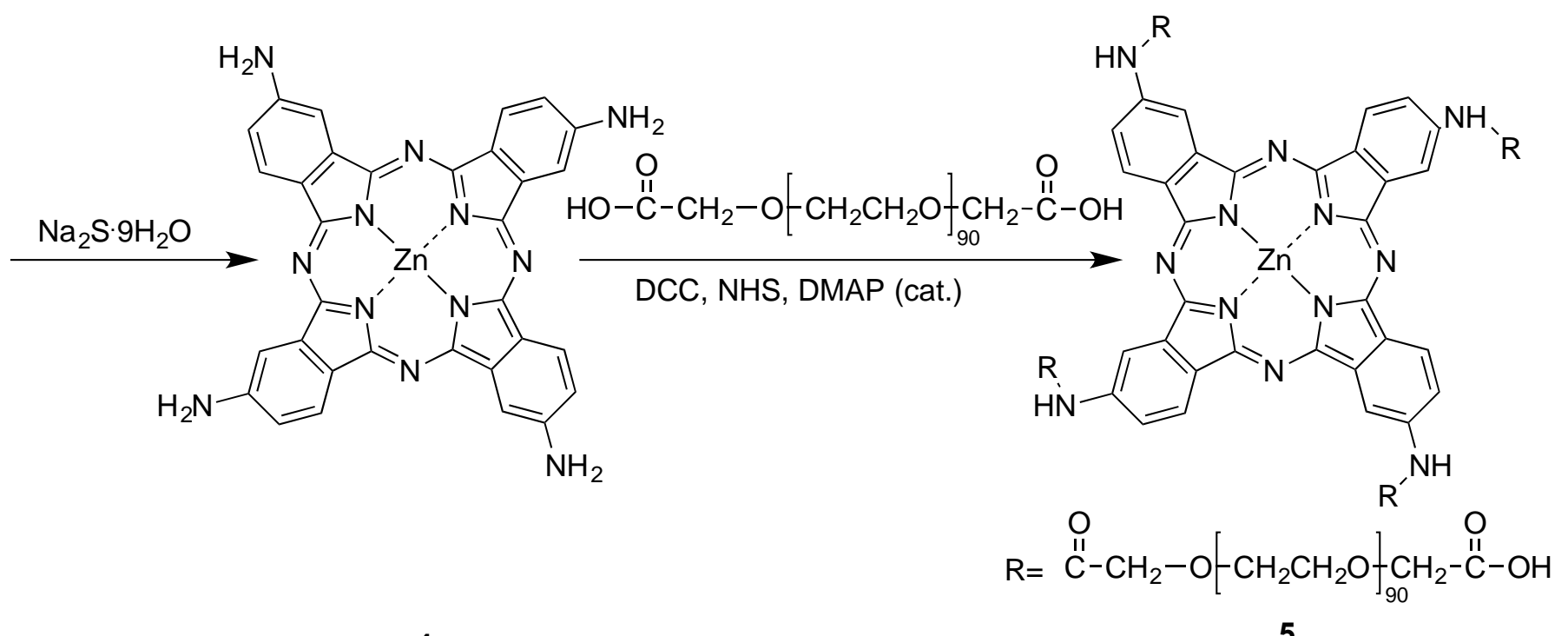

4

5

Scheme 2. Synthesis of zinc(II) phthalocyanine hydrophilic derivative (ZnPc) 5.

The synthesis of zinc tetraaminophthalocyanine 4 was accomplished via a two-step reaction with 4nitrophthalimide 2, urea and zinc chloride hexahydrate as starting materials in presence of ammonium molybdate as the catalyst. The obtained zinc tetranitrophthalocyanine 3, was converted into zinc tetraaminophthalocyanine 4 by reduction with sodium sulfide. Strong absorptions at 3330 and $3206 \mathrm{~cm}^{-1}$ in the FT-IR spectrum of $\mathbf{4}$ were attributed to stretching vibrations of peripheral amine groups, while a strong absorption at $1604 \mathrm{~cm}^{-1}$ was contributed to their bending vibrations. Generally, peaks observed in the FT-IR spectra of compound $\mathbf{4}$ were nearly the same as for very similar nickel tetraaminophthalocyanine, described by Pavaskar et al. ${ }^{18}$ The chemical identity of the obtained zinc tetraaminophthalocyanine 4 was additionally confirmed by ${ }^{1} \mathrm{H}$ NMR analysis, which revealed signals from aromatic protons at 8.05-9.65 ppm confirming the presence of aromatic moieties characteristic for phthalocyanine structures. The desired compound was obtained in very good yield (over 90\%), exceeding the yields of similar nickel tetraaminophthalocyanine (about $61 \%)$, synthesized by Pavaskar et al.. ${ }^{18}$

For further synthesis of poly(ethylene oxide) modified zinc(II) phthalocyanine 5, employment of a tetra ( $\mathrm{N}$ carbonylacrylic) aminophthalocyanine derivative was initially considered, because esterification of the carboxylic acid group with standard poly(ethylene glycol) is an approved and easy method of its PEG-ylation. According to Pavaskar et al. ${ }^{18}$ a tetra ( $\mathrm{N}$-carbonylacrylic) aminophthalocyanine derivative has been synthesized 
by zinc tetraaminophthalocyanine reaction with maleic anhydride, and coupled with poly(ethylene oxide) by Steglich esterification. Unfortunately the obtained product was scarcely soluble in water, which made it impossible to apply it as a hydrophilic fluorescent marker, although introducing a carboxyl group into zinc tetraaminophthalocyanine is easier than into poly(ethylene oxide). For this reason, the product of carboxylic acid terminated poly(ethylene glycol) and zinc tetraaminophthalocyanine coupling, which was more difficult to obtain, was synthesized and used further in conjugation with block copolymers.

Signals observed in the ${ }^{1} \mathrm{H}$ NMR spectra at 8.05-9.65 ppm from $\mathrm{CH}$ protons of the obtained poly(ethylene oxide) modified zinc(II) phthalocyanine 5 and both ZnPc-conjugated block copolymers revealed that these compounds contain aromatic rings, and was confirmed by characteristic bands observed in the FT-IR spectrum at about $730-744 \mathrm{~cm}^{-1}$, attributed to $\mathrm{C}-\mathrm{C}$ and $\mathrm{C}-\mathrm{H}$ bonds present also in aromatic moieties. Moreover in ${ }^{1} \mathrm{H}$ NMR spectra recorded for poly(ethylene oxide) modified zinc(II) phthalocyanine, performed in $\mathrm{D}_{2} \mathrm{O}$, complete structural resolution of the whole molecule was possible, due to presence of both PEG (3.67 ppm and 4.15 ppm for end groups) and aromatic (8.05-9.65 ppm) protons with proper integration, while the fluorescence emission $\left(\lambda_{\text {ex }} 354 \mathrm{~nm}\right.$ ) spectrum of its aqueous solution contained a characteristic band with the maximum at about $\lambda 430 \mathrm{~nm}$ (Figure S1). These results clearly show that the obtained compound is molecularly dissolved in aqueous solution with no sign of aggregation. According to our investigations, the obtained ZnPc-conjugated block copolymers are good candidates for preparation of polymeric micelles with functionalized corona.

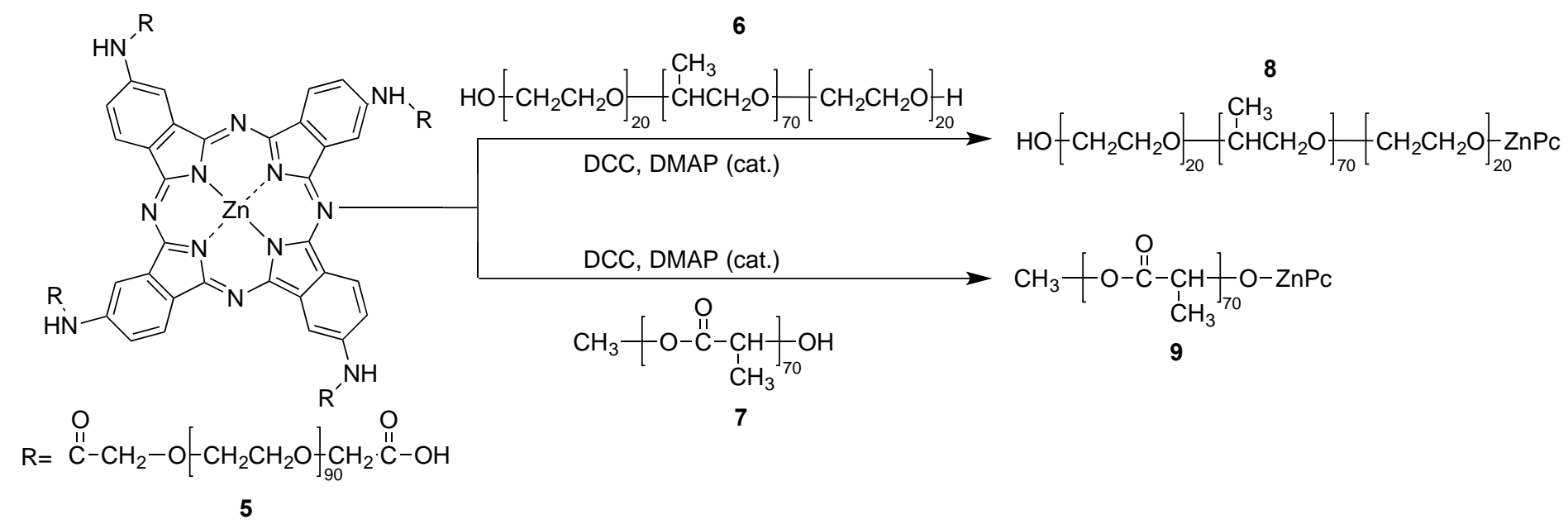

Scheme 3. Synthetic routes to Pluronic and PLLA block copolymers conjugated with zinc(II) phthalocyanine derivatives $(\mathrm{ZnPc}) \mathbf{8}$ and $\mathbf{9}$.

In order to prepare poly(ethylene oxide) modified zinc(II) phthalocyanine (ZnPc) 5, as well as to prepare both zinc(II) phthalocyanine modified block copolymers $\mathbf{8}$ and $\mathbf{9}$, reactions in Steglich conditions were necessary, due to the risk of poly(ethylene glycol) derivatives or block copolymers degradation. For poly(ethylene oxide) modified zinc(II) phthalocyanine (5) reaction with $N$-hydroxysuccinimide was performed (Scheme 2), while for both block copolymers - the Steglich esterification with $N, N$-dicyclohexylcarbodiimide (Scheme 3) was used. In order to avoid residues of unreacted poly(ethylene oxide) (difficult to remove) modified zinc(II) phthalocyanine 5, excess of Pluronic P123 ((poly(ethylene oxide)-b-poly(propylene oxide)-bpoly(ethylene oxide)) 6 or poly(L-lactide) (PLLA) 7 was used in the reaction mixture. Purification of 5, as well as purification of zinc phthalocyanine modified Pluronic P123 8, involved dialysis to remove excess reagents carboxylic terminated poly(ethylene glycol) $\mathbf{1}$ or Pluronic P123 6, respectively. For zinc phthalocyanine 
modified PLLA 9 excess of polyester was removed by precipitation from THF, followed by filtration. Generally, both zinc(II) phthalocyanine modified block copolymers 8 and $\mathbf{9}$ were obtained conveniently in multistep reactions with high yields (at least 60\%) (Scheme 3).

\section{Preparation and characterization of polymeric micelles}

Polymeric micelle systems were prepared using two different approaches: the thin film method for Pluronic micelles (System 1) and modified interfacial polymer deposition - solvent evaporation technique for poly(L-lactide)-derived polymeric micelles (System 2), due to different properties of these block copolymers. Pluronic P123 and its functionalized derivatives $\mathbf{8}$ are waxy solids or pastes with an ability to self-assemble during temperature decrease from about $60-50{ }^{\circ} \mathrm{C}$ to below $35^{\circ} \mathrm{C}$, so the most appropriate and efficient method for micelle preparation of these is the thin film method. Poly(L-lactide) (PEG-b-PLLA) block copolymers are semi-crystalline solids and the process of micelle formation is driven by the surface tension on the liquidliquid interface, so methods utilizing dropwise addition of cosolvent and/or emulsification are required for their preparation.

The average size of the obtained polymeric micelles (expressed as hydrodynamic diameter, $D_{H}$ ) ranged from around $15 \mathrm{~nm}$ (Pluronic micelles, $\mathbf{1 a}$ and $\mathbf{1 b}$ ) to $89 \mathrm{~nm}$ (functionalized PLLA block copolymer micelles, 2b) (Table 1), and was consistent with our previous studies of Pluronic ${ }^{28}$ and poly(L-lactide) block copolymer micelles. ${ }^{24}$ Moreover, the obtained nanocarriers had a narrow size distribution (Pdl < 0.3) (Table 1), which could make them good candidates as nanocarriers useful for example in cancer treatment. AFM imaging confirmed the DLS data of the obtained polymeric micelles (Figure S2), since spherical and moderately uniform particles were observed. The dimensions of the obtained nanosystems are amenable to avoiding clearance by first pass renal filtration as well as detection by the phagocytic system and consequently they may achieve a longer circulation time in the bloodstream.

Table 1. Characteristics of the polymeric micelles composed of block copolymers and functionalized with covalently bound hydrophilic zinc(II) phthalocyanine (ZnPc)

\begin{tabular}{|c|c|c|c|c|}
\hline \multirow{2}{*}{$\begin{array}{l}\text { Micelle } \\
\text { system }\end{array}$} & \multicolumn{2}{|c|}{ Copolymer $(\mathrm{mg} / \mathrm{ml})$} & \multirow{2}{*}{$\begin{array}{c}\mathrm{D}_{\mathrm{H}^{\mathrm{a}}} \\
(\mathrm{nm})\end{array}$} & \multirow{2}{*}{$P d l^{b}$} \\
\hline & Pluronic P123 & PLLA & & \\
\hline 1a & 10.2 & & 14 & 0.16 \\
\hline $1 b$ & $10.2(+Z n P c)$ & & 14 & 0.26 \\
\hline $2 a$ & & 4.0 (+PEG) & 24 & 0.23 \\
\hline $2 b$ & & $4.0(+\mathrm{ZnPc})$ & 75 & 0.09 \\
\hline
\end{tabular}

${ }^{a} D_{H}$ hydrodynamic diameter. ${ }^{b}$ Pdl polydispersity index.

ZnPc-conjugated polymeric micelles were designed to evaluate their possible role as therapeutic nanocarriers containing a fluorescent marker, chemically attached to their corona. Fluorescence spectroscopy was utilized to confirm the presence of the fluorescent marker ( $\mathrm{ZnPc}$ ) and its activity in the studied 
nanosystems (Figure S3). The results obtained clearly indicate that the polymeric micelles studied are good candidates as multifunctional transport agents, due to their ability to give a fluorescence response.

\section{Biological studies}

The results of biological studies are presented in Figure 1. The viability, measured by two independent assays, indicated that polymeric micelles with and without fluorescent marker ( $\mathrm{nPC}$ ) are not cytotoxic to the melanoma cells (MeWo). There was observed an insignificant decrease of cellular viability for micelle systems $\mathbf{1 a}$ and $\mathbf{1 b}$ (Figure $\mathbf{1 a}$ ). Micelle systems $\mathbf{2 a}$ and $\mathbf{2 b}$ did not exhibit any destructive effect on mitochondrial activity (Figure 1a) or ATP production (Figure 1b). The evaluated functionalized micellar systems induced activity of caspase $3 / 7$ on the level of control cells activities (Figure 1c). The results obtained indicate that micelles functionalized with ZnPc are safe for in vitro study and did not affect crucial cellular parameters. Additionally, an intracellular distribution of PMs (system 2b) in MeWo cells was shown after 24 hours incubation (Figure 1d), as we could observe ZnPc localized mainly in the cytoplasm of melanoma cells.

a.

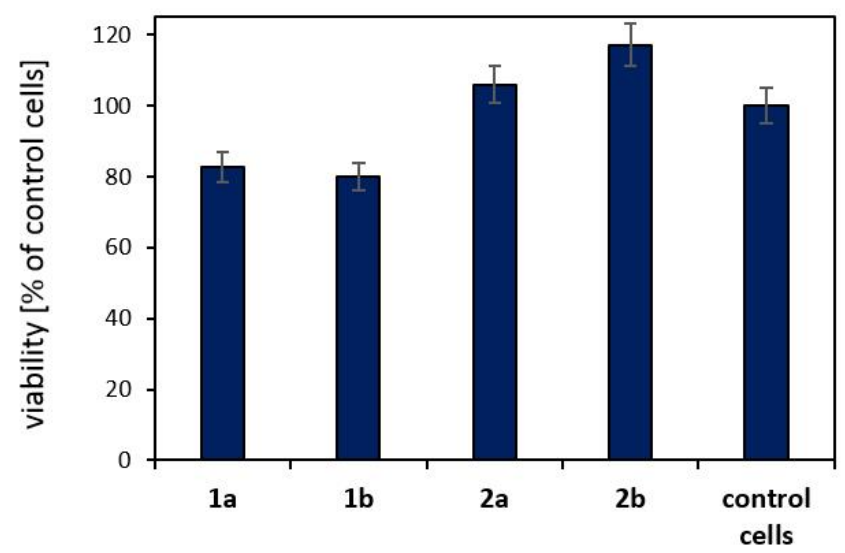

c.

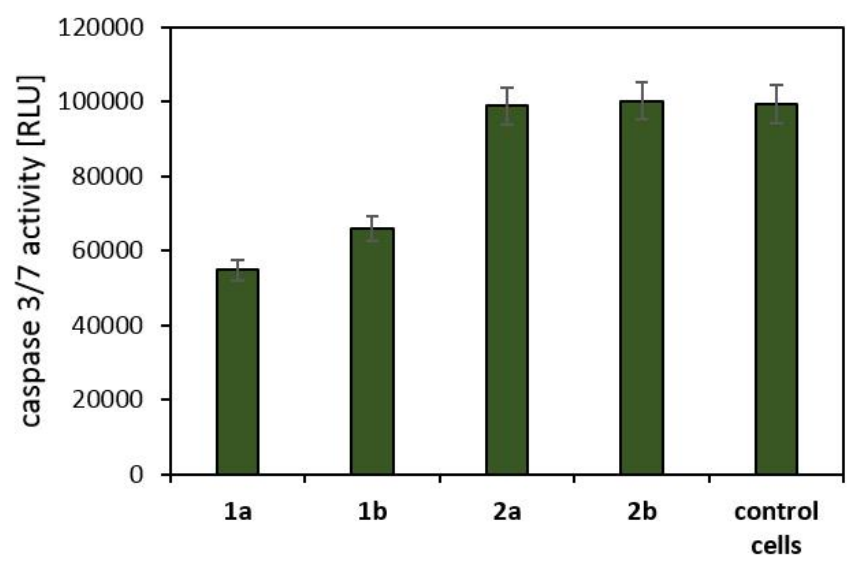

b.

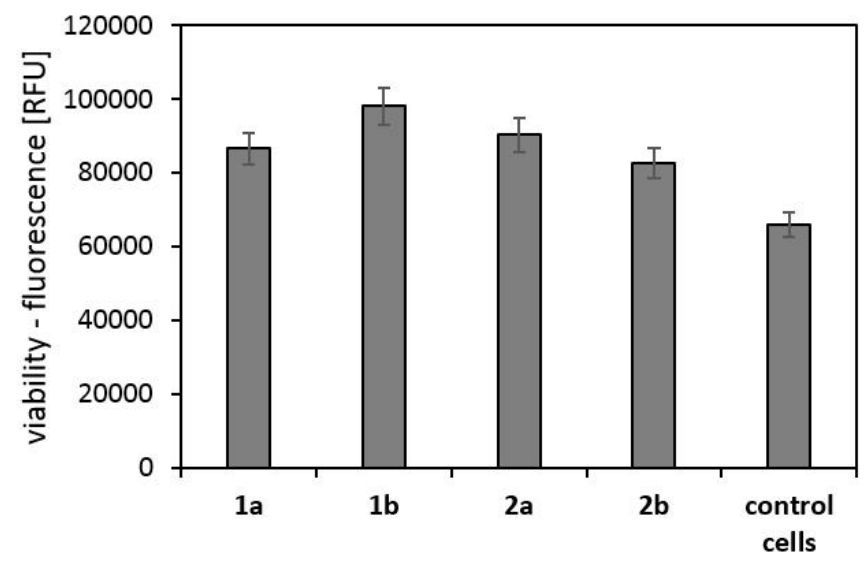

d.

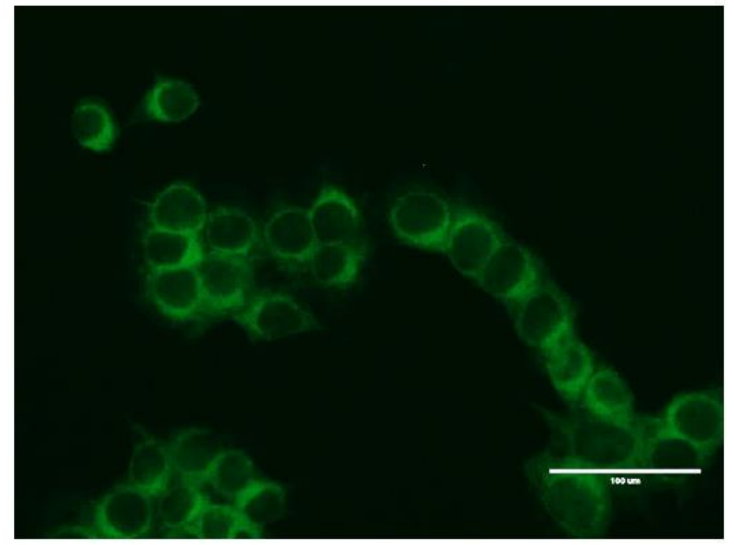

Figure 1. The evaluation of biological effect of functionalized micelles measured after 24 hours of incubation in MeWo cells: a. cellular viability measured by MTT assay; $b$. cellular viability measured by fluorescent ATP assay; c. activity of caspase-3/7 measured by luminescent assay; $\mathbf{d}$. intracellular distribution of PMs (system $\mathbf{2 b})$ after $24 \mathrm{~h}$ of incubation. See descriptions for the systems $\mathbf{1} \mathbf{a}-\mathbf{b}$ and $\mathbf{2} \mathbf{a}-\mathbf{b}$ in Table 1. 
The results obtained indicate that polymeric micelles based on Pluronic 123 and PLLA conjugates with fluorescent marker $(\mathrm{ZnPc})$ are safe and the nanosystems do not cause cell death. Those functionalized polymeric micelle systems may act as an effective drug delivery system. Our previous study on polymeric micelles loaded with hydrophobic zinc(II) phthalocyanine indicated that these micelles can be effective nanocarriers in photodynamic reactions in metastatic melanoma cells (Me45). Additionally, the mentioned micelles, both empty and loaded with anticancer cargo, appear to be haemato-biocompatible and safe for normal keratinocytes, macrophages and endothelial cells. ${ }^{24}$

\section{Conclusion}

The present contribution is focused on the synthesis and characterization of hydrophilic derivatives of zinc(II) phthalocyanine conjugates with Pluronic P123 and PLLA. The hydrophilic ZnPc was prepared conveniently in a multistep process including cyclotetramerization of 4-nitrophthalimide, reduction of the tetranitrophthalocyanine and coupling with previously synthesized carboxy-terminated poly(ethylene oxide). For the synthesis of two different ZnPc-conjugated block copolymers, Steglich esterification was utilized giving the desired products in good yields. The fabricated polymeric micelles, grafted with the zinc(II) phthalocyanine-type function, exhibited good physical stability and appropriate size (less than about $100 \mathrm{~nm}$ ) combined with low polydispersity indexes ( $\mathrm{Pdl}<0.3)$. Biological investigation of the nanocarriers obtained, including MTT assay cytotoxicity in human melanoma cells (MeWo) as well as the proapoptotic potential by the detection of caspase 3/7 activity, confirmed a lack of their cytotoxicity, while intracellular distribution - localization of PMs (system 2b) in cytoplasm. These results indicate the ZnPc-functionalized polymeric micelles constitute a promising addition to the inventory in cancer therapy and diagnostics, and additionally to monitor the efficiency of chemotherapy.

\section{Experimental Section}

\section{Chemistry}

General. ${ }^{1} \mathrm{H}$ NMR spectra were recorded on Bruker AMX600 spectrophotometer (Rheinstetten, Germany) and chemical shifts were referenced to TMS signal as an external standard (in $\mathrm{CDCl}_{3}$ ), while IR spectra on a Fourier transform, Bruker VERTEX $70 \mathrm{~V}$ vacuum spectrometer (Rheinstetten, Germany) with samples placed on the diamond crystal of the ATR accessory. Melting points were determined on a Boetius melting point apparatus and have not been corrected. Chemicals used were purchased from Sigma-Aldrich (including deuterated solvents), Fluka ( $N, N^{\prime}$-dicyclohexylcarbodimide, ethyl bromoacetate, potassium), Avantor Performace Materials (solvents and urea), Schuchart (tert-amyl alcohol) and Akina, inc (methoxypoly(ethylene oxide)-bpoly(L-lactide) block copolymer, PEG-b-PLLA) were of analytical grade. tert-Amyl alcohol was dried over $\mathrm{CaH}_{2}$ and distilled before use, while other solvents and reagents were used as received.

Synthetic procedure for carboxyl terminated poly(ethylene glycol) (1). Potassium (2.40 g, 60 mmol) was dissolved in tert-amyl alcohol $(50 \mathrm{~mL})$ under a protecting atmosphere of nitrogen. After complete dissolution of the potassium, poly(ethylene glycol) (PEG) (12.00 g, $3 \mathrm{mmol}$, MW 4000$)$ was added and the mixture stirred at $50{ }^{\circ} \mathrm{C}$ for $8 \mathrm{~h}$ in a nitrogen atmosphere. Ethyl bromoacetate $(6.64 \mathrm{~mL}, 60 \mathrm{mmol}$ ) was added dropwise, then stirring at $50{ }^{\circ} \mathrm{C}$ was continued for $24 \mathrm{~h}$. After completion of reaction, excess tert-amyl alcohol was 
evaporated. The residue was dissolved in $0.1 \mathrm{M} \mathrm{NaOH}(70 \mathrm{~mL})$ and stirred for $8 \mathrm{~h}$ at ambient temperature. After adjusting the $\mathrm{pH}$ to 3 with $0.1 \mathrm{M} \mathrm{HCl}$, the reaction mixture was extracted with $\mathrm{CH}_{2} \mathrm{Cl}_{2}(3 \times 20 \mathrm{~mL})$, dried over anhydrous $\mathrm{MgSO}_{4}$, filtered and evaporated in vacuum. The residue was dissolved in minimal amount of $\mathrm{CH}_{2} \mathrm{Cl}_{2}$ and precipitated from cold $\mathrm{Et}_{2} \mathrm{O}$ to obtain 1.

White solid, yield 90\%, $10.07 \mathrm{~g}$; IR (film, $\left.\mathrm{v}_{\max } \mathrm{cm}^{-1}\right)$ : 2882 (C-H, stretching), 1749 (C=O, stretching), 1466 ( $\mathrm{CH}_{2}$, scissoring), 1359 and 1341 ( $\mathrm{CH}_{2}$, wagging), 1279 ( $\mathrm{CH}_{2}$, twisting), 1104 (C-O-C, twisting), 958 (C-O-C, vibration and $\mathrm{CH}_{2}$, rocking), $841\left(\mathrm{CH}_{2}\right.$, rocking), 529 (C-O-C, bending). $\left.{ }^{1} \mathrm{H} \mathrm{NMR}\left(600 \mathrm{MHz}^{\mathrm{CDCl}}\right)_{3}\right): \delta_{H} 3.65(360 \mathrm{H}, \mathrm{s}$, $\left.\left(\mathrm{OCH}_{2} \mathrm{CH}_{2}\right)_{90}\right), 4.15\left(4 \mathrm{H}, \mathrm{s}, 2 \times \mathrm{OCH}_{2} \mathrm{COOH}\right)$.

4-Nitrophthalimide (2). To fuming, $100 \% \mathrm{HNO}_{3}(20 \mathrm{~mL})$, conc $\mathrm{H}_{2} \mathrm{SO}_{4}(80 \mathrm{~mL})$ was slowly added and the mixture cooled in an ice bath. To the obtained mixture phthalimide (15 g, $0.1 \mathrm{~mol})$ was added in portions over a 15min interval with stirring at a temperature under $15^{\circ} \mathrm{C}$, then the temperature was raised to about $35^{\circ} \mathrm{C}$ and held for $45 \mathrm{~min}$. After completion of the reaction the mixture was cooled to $0{ }^{\circ} \mathrm{C}$ and slowly added to ice $(375$ g) at such a rate that the temperature remained below $15^{\circ} \mathrm{C}$. The precipitated crude product was collected by vacuum filtration, washed with cold water, dried at $\mathrm{rt}$ and purified by recrystallization from anhydrous EtOH. Pale yellow crystals, yield $61 \%, 11.70 \mathrm{~g}$, mp $194.5-195{ }^{\circ} \mathrm{C}$ (lit. ${ }^{27}$ m.p. $\left.194.5-195{ }^{\circ} \mathrm{C}\right) .{ }^{1} \mathrm{H} \mathrm{NMR}(600 \mathrm{MHz}, \mathrm{DMSO}-$ $\left.d_{6}\right): \delta_{H} 8.00\left(1 \mathrm{H}_{\text {arom }}, d,{ }^{2} J_{H H} 5.7 \mathrm{~Hz}\right), 8.34\left(1 \mathrm{H}_{\text {arom }}, \mathrm{s}\right), 8.54\left(1 \mathrm{H}_{\text {arom }}, \mathrm{d},{ }^{2} J_{\mathrm{HH}} 6.9 \mathrm{~Hz}\right), 11.76(1 \mathrm{H}, \mathrm{s}, \mathrm{NH})$.

Zinc tetraaminophthalocyanine (4). 4-Nitrophthalimide (2) (1.95 g, $10 \mathrm{mmol})$, urea ( $3 \mathrm{~g}, 50 \mathrm{mmol}), \mathrm{ZnCl}_{2} \cdot 6 \mathrm{H}_{2} \mathrm{O}$ $(0.43 \mathrm{~g}, 2.5 \mathrm{mmol})$ and ammonium molybdate $(0.15 \mathrm{~g}, 0.76 \mathrm{mmol})$ were finely ground, transferred into a round bottom flask and heated to 180 and $200{ }^{\circ} \mathrm{C}$ for $3 \mathrm{~h}$ under a protecting atmosphere of nitrogen. The obtained solid was treated with $\mathrm{HCl}(50 \mathrm{~mL}, 1 \mathrm{M})$ followed by $\mathrm{NaOH}(50 \mathrm{~mL}, 1 \mathrm{M})$, ground, washed with water (until $\mathrm{Cl}^{-}$ ions were not present in the filtrate) and dried in vacuum. To the obtained dark green solid (dissolved in $N, N$ dimethylformamide $(150 \mathrm{~mL})$ ) solution sodium sulfide nonahydrate $(9 \mathrm{~g}, 28 \mathrm{mmol})$, dissolved in minimal amount of water, was added and mixture was stirred for $3 \mathrm{~h}$ at $60^{\circ} \mathrm{C}$ under nitrogen. After completion of the reaction, solvents were removed under reduced pressure followed by addition of water (100 $\mathrm{mL})$ to the residues. The product 4 was separated by filtration as a dark green solid and washed several times with distilled water as well as repeatedly with $\mathrm{MeOH} / \mathrm{Et}_{2} \mathrm{O}(1: 10, \mathrm{v}: \mathrm{v})$ mixture and EtOAc followed by drying in vacuum at $60^{\circ} \mathrm{C}$.

Dark green solid, yield 91\%, $1.45 \mathrm{~g}$; IR $\left(\mathrm{V}_{\max }, \mathrm{cm}^{-1}\right)$ : 3330 and $3206(\mathrm{~N}-\mathrm{H}$, stretching), $1604(\mathrm{~N}-\mathrm{H}$, bending), 1492 (C-N, stretching), 744 (plane, skeletal), $728\left(\mathrm{C}-\mathrm{H}\right.$, out-of-plane, aromatic). ${ }^{1} \mathrm{H}$ NMR (600 MHz, DMSO-d 6 ): $\delta_{H}$ 8.05-9.65 (12 $\left.\mathrm{H}_{\text {arom, }} \mathrm{m}, \mathrm{CH}\right)$.

Hydrophilic derivative of zinc(II) phthalocyanine (ZnPc) (5). Carboxylic acid terminated poly(ethylene glycol) $(6.44 \mathrm{~g}, 1.6 \mathrm{mmol}) \mathbf{1}$, zinc tetraaminophthalocyanine $(0.1 \mathrm{~g}, 0.16 \mathrm{mmol}) 4, \mathrm{~N}, \mathrm{~N}$-dicyclohexylocarbodiimide (1.29 g, $6.3 \mathrm{mmol}), N$-hydroxysuccinimide $(0.72 \mathrm{~g}, 6.3 \mathrm{~mole})$ and 4-dimethylaminopyridine (in catalytic amount) were dissolved in dry THF $(50 \mathrm{~mL})$ and stirred in the dark for $48 \mathrm{~h}$. After completion of the reaction the precipited $\mathrm{N}, \mathrm{N}$-dicyclohexylurea was removed by filtration and this was followed by solvent evaporation under reduced pressure. Water $(150 \mathrm{~mL})$ was added followed by solution dialysis $(4 \times 2 \mathrm{~L}, 3$ days, MWCO 8000). Then obtained solution was additionally filtered and freeze-dried.

Pale green solid, yield 98\%, $2.61 \mathrm{~g}$; IR (film, $\mathrm{V}_{\max } \mathrm{cm}^{-1}$ ): 2882 (C-H, stretching), 1749 (C=O, stretching), 1466 ( $\mathrm{CH}_{2}$, scissoring), 1359 and 1341 ( $\mathrm{CH}_{2}$, wagging), 1279 ( $\mathrm{CH}_{2}$, twisting), 1104 (C-O-C, twisting), 958 (C-O-C, vibration and $\mathrm{CH}_{2}$, rocking), 841 ( $\mathrm{CH}_{2}$, rocking), $729\left(\mathrm{C}-\mathrm{H}\right.$, out-of-plane, aromatic), 529 (C-O-C, bending). ${ }^{1} \mathrm{H}$ NMR $\left(600 \mathrm{MHz}, \mathrm{CDCl}_{3}\right): \delta_{H} 3.65\left(1440 \mathrm{H}, \mathrm{s},\left(\mathrm{OCH}_{2} \mathrm{CH}_{2}\right)_{90}\right), 4.15\left(16 \mathrm{H}, \mathrm{s}, \mathrm{OCH}_{2} \mathrm{CO}\right)$, 8.05-9.65 (12Harom, m, CH).

Zinc phthalocyanine modified Pluronic P123 (8). ZnPc (0.40 g, $0.0235 \mathrm{mmol})$ 5, Pluronic P123 (1.36 g, 0.047 mmol, MW 5 800) 6, N,N-dicyclohexylocarbodiimide (0.05 g, $0.135 \mathrm{mmol}$ ) and 4-dimethylaminepyridine (in 
catalytic amount) were dissolved in dry THF $(50 \mathrm{~mL})$ and stirred in the dark for $72 \mathrm{~h}$. After completion of the reaction, the precipited $N, N$-dicyclohexylurea was removed by filtration followed by solvent evaporation under reduced pressure. The obtained solid was dissolved in THF, filtered and solvent was removed under reduced pressure. To the obtained residue water $(100 \mathrm{~mL})$ was added followed by solution dialysis $(4 \times 2 \mathrm{~L}, 3$ days, MWCO 8 000). The obtained solution was additionally filtered and freeze-dried.

Dark green, waxy solid, yield 86\%, $0.545 \mathrm{~g}$; IR (film, $\left.\mathrm{v}_{\max }, \mathrm{cm}^{-1}\right)$ : $2875(\mathrm{C}-\mathrm{H}$, stretching), 1727 (C=O, stretching), $1466\left(\mathrm{CH}_{2}\right.$, scissoring), 1360 and $1343\left(\mathrm{CH}_{2}\right.$, wagging), $1280\left(\mathrm{CH}_{2}\right.$, twisting), 1101 (C-O-C, twisting), 963 (C-O-C, vibration and $\mathrm{CH}_{2}$, rocking), $842\left(\mathrm{CH}_{2}\right.$, rocking), 744 (plane, skeletal), 528 (C-O-C, bending). ${ }^{1} \mathrm{H} \mathrm{NMR}(600 \mathrm{MHz}$, $\left.\mathrm{Me}_{2} \mathrm{CO}-d_{6}\right): \delta_{H} 1.24-1.25\left(210 \mathrm{H}, \mathrm{m},\left(\mathrm{OCH}\left(\mathrm{CH}_{3}\right) \mathrm{CH}_{2}\right){ }_{70}\right), 3.40\left(70 \mathrm{H}, \mathrm{m},\left(\mathrm{OC} \underline{\mathrm{H}}\left(\mathrm{CH}_{3}\right) \mathrm{CH}_{2}\right) 70\right), 3.55(140 \mathrm{H}, \mathrm{m}$, $\left.\left(\mathrm{OCH}\left(\mathrm{CH}_{3}\right) \mathrm{CH}_{2}\right)_{70}\right), 3.64\left(1600 \mathrm{H}, \mathrm{s}, 4 \times\left(\mathrm{OCH}_{2} \mathrm{CH}_{2}\right)_{90}+2 x\left(\mathrm{OCH}_{2} \mathrm{CH}_{2}\right)_{20}\right), 4.15\left(16 \mathrm{H}, \mathrm{s}, \mathrm{OCH}_{2} \mathrm{CO}\right), 8.05-9.65\left(12 \mathrm{H}_{\text {arom, }}\right.$ $\mathrm{m}, \mathrm{CH})$.

Zinc phthalocyanine modified poly(L-lactide) (9). ZnPc (0.4 g, $0.0235 \mathrm{mmol})$ 5, poly(L-lactide) $(0.235 \mathrm{~g}, 0.047$ mmol, MW 5000) 7, N,N-dicyclohexylocarbodiimide (0.05 g, $0.135 \mathrm{mmol}$ ) and 4-dimethylaminopyridine (in catalytic amount) were dissolved in dry $\mathrm{THF} / \mathrm{CH}_{2} \mathrm{Cl}_{2}(50 \mathrm{~mL})(1: 1, \mathrm{v}: \mathrm{v})$ mixture and stirred at dark for $72 \mathrm{~h}$. After completion of reaction the precipited $\mathrm{N}, \mathrm{N}$-dicyclohexylurea was removed by filtration followed by solvent evaporation under reduced pressure. The solid obtained was dissolved in THF, filtered and solvent was removed under reduced pressure.

Pale green, waxy solid, yield 60\%, $1.02 \mathrm{~g}$; IR (film, $\left.\mathrm{V}_{\max } \mathrm{cm}^{-1}\right): 2887(\mathrm{C}-\mathrm{H}$, stretching), 1758 (C=O, stretching), $1455\left(\mathrm{CH}_{2}\right.$, scissoring and $\mathrm{CH}_{3}$, bending), 1359 and $1343\left(\mathrm{CH}_{2}\right.$, wagging), $1279\left(\mathrm{CH}_{2}\right.$, twisting), 1188 (C-O-C, vibration in poly(L-lactide) chain), 1104 (C-O-C, twisting), 962 (C-O-C, vibration and $\mathrm{CH}_{2}$, rocking), 842 ( $\mathrm{CH}_{2}$, rocking), 736 (C-H, out-of-plane, aromatic), 529 (C-O-C, bending). ${ }^{1} \mathrm{H} \mathrm{NMR}\left(600 \mathrm{MHz}, \mathrm{CDCl}_{3}\right): \delta_{H} 1.61(210 \mathrm{H}, \mathrm{m}$, $\left.\left(\mathrm{COCH}\left(\mathrm{CH}_{3}\right) \mathrm{O}\right)_{70}\right), 3.65\left(1440 \mathrm{H}, \mathrm{s},\left(\mathrm{OCH}_{2} \mathrm{CH}_{2}\right)_{90}\right), 4.15\left(16 \mathrm{H}, \mathrm{s}, \mathrm{OCH}_{2} \mathrm{CO}-\right), 5.20\left(70 \mathrm{H}, \mathrm{m},\left(\mathrm{COC} \underline{\mathrm{H}}\left(\mathrm{CH}_{3}\right) \mathrm{O}\right)_{70}\right), 8.05-$ $9.65\left(12 \mathrm{H}_{\text {arom }}, \mathrm{m}, \mathrm{CH}\right)$.

\section{General procedures for polymeric micelles}

Preparation of polymeric micelles. Polymeric micelles with covalently bound ZnPc were prepared by the thin film method (for Pluronic micelles, System 1) and by modified interfacial polymer deposition-solvent evaporation technique (for micelles of poly(L-lactide) derivatives, System 2). Briefly, block copolymers (including their hydrophilic zinc phthalocyanine modified derivatives) were dissolved in appropriate organic solvents: $\mathrm{Me}_{2} \mathrm{CO} / \mathrm{MeOH}(4: 1, \mathrm{v}: \mathrm{v})$ mixture for Pluronic micelles and THF for poly(L-lactide) (PLLA) micelles (PLLA micelles with no fluorescent marker were composed of PEG-b-PLLA instead of ZnPc-conjugated PLLA). Then, in the thin film method, the obtained solution was placed in round bottom flask and the organic solvent was removed under reduced pressure, followed by hydration of the resulting thin film. In interfacial polymer deposition-solvent evaporation technique the obtained organic solutions were slowly added to stirred water and THF was removed under reduced pressure at rt. In both methods, polymeric micelles solutions were filtered through syringe filters to remove undissolved substances.

Characterization of polymeric micelles. The size distribution (expressed as the hydrodynamic diameter $D_{H}$ ) and polydispersity index (Pdl) of the polymeric micelles were determined by dynamic light scattering (DLS) measurements using a Zetasizer NanoZS Instrument (ZEM4228, Malvern Instruments, UK) equipped with a 4 $\mathrm{mW}$ He-Ne laser $(\lambda 633 \mathrm{~nm}$ ) and with noninvasive backscattering (NIBS) detection at a scattering angle of $173^{\circ}$. Samples were equilibrated for a minimum of $1 \mathrm{~min}$ at $25^{\circ} \mathrm{C}$ before measurements. The morphology and dimensions of the polymeric micelles were examined by atomic force microscopy (AFM) using the Veeco NanoScope Dimension V AFM with an RT ESP Veeco tube scanner. The scanning speed was $0.5 \mathrm{~Hz}$ and a low- 
resonance-frequency pyramidal silicon cantilever resonating at 250-331 kHz was employed (at a constant force of $20-80 \mathrm{~N} / \mathrm{m}$ ). Before observations, the polymeric micelles solutions (system $1-10.2 \mathrm{mg} / \mathrm{mL}$, system 2 $-4.0 \mathrm{mg} / \mathrm{mL}$ ) were diluted 15 times in double-distilled water and placed on a cover glass surface and allowed to dry at rt. Then the excess of micelles was removed by rinsing the surfaces in double-distilled water for 30 min and drying at rt. The fluorescence spectra were recorded on a Spectrofluorimeter F4500 (Hitachi, Japan) with scan speed $240 \mathrm{~nm} / \mathrm{min}$ and delay equal to $0.5 \mathrm{~s}$. Properties of the obtained polymeric micelles systems are presented in Table 1.

\section{Biological evaluation}

Cell human malignant melanoma cells (MeWo) line was obtained from European Collection of Authenticated Cell Cultures (ECACC). DMEM medium, PBS, antibiotics, trypsin, 3(4,5-dimethylthiazol-2-yl)-2,5diphenyltetrazolium bromide and EDTA were purchased form Sigma, Poland. Fetal bovine serum was purchased from Biowhittaker, and ApoLive-GloTM Multiplex Assay was purchased from Promega, Poland.

Cell culture. The studies were performed on human malignant melanoma cells (MeWo). MeWo cells were grown in DMEM medium with addition of $10 \%$ fetal bovine serum (FBS) and supplemented by antibiotics (Penicillin/streptomycin). For the experiments cells were removed by trypsinization (trypsin $0.025 \%$ and EDTA $0.02 \%$ solution) and rinsed twice with PBS.

Cytotoxic activity. Cells survival was evaluated by the 3(4,5-dimethylthiazol-2-yl)-2,5-diphenyltetrazolium bromide (MTT) assay. The cells were seeded into 96-well microculture plates at the density of $5 \times 10^{3}$ cells/well. Cell viability was determined after $24 \mathrm{~h}$ for standard cytotoxicity with polymeric micelles with and without fluorescent marker. The MTT assay was performed according to the manufacturer's protocol. The absorbance was determined using a multiwell scanning spectrophotometer at $\lambda 570 \mathrm{~nm}$ (EnSpire Perkin Elmer, Poland). Mitochondrial function was expressed as a percentage of viable cells under treatment relative to untreated control cells. The results are presented as the mean \pm the standard deviation of the triplicates.

Caspase-3/7 activity. Caspase-3/7 activity was measured using the ApoLive-GloTM Multiplex Assay according to the manufacturer's protocol. The applied assay enables measuring viability and caspase $3 / 7$ activation in the same sample well. MeWo cells were plated in triplicate in 96-well cell culture plates (Black/White Isoplate96 TC, Black Frame, White Well, Perkin Elmer, Poland) and left overnight at 37 aC. Then the $24 \mathrm{~h}$ incubation with polymeric micelles with and without fluorescent marker was performed. At that time the first stage was evaluated - protease as a marker of cell viability was measured. The measurement was performed by fluorescence detection at an excitation/emission wavelength of $\lambda$ 400/505 $\mathrm{nm}$ with a multifunctional microplate reader (EnSpire Perkin Elmer, Poland). Then caspase 3/7, substrate for luciferase, which contains tetrapeptide sequence DEVD, was added and after 30 min of incubation at rt luminescence was measured. Results are presented as the mean \pm the standard deviation of the triplicates.

ZnPc distribution. MeWo cells were prepared for fluorescent studies. Cells were primarily harvested on cover slides. The exemplary nanomicelles (system $2 \mathrm{~b}$ ) in concentration of $4 \mu \mathrm{M}$ were diluted in medium and added to cells for $24 \mathrm{~h}$ incubation. Then cells were washed with PBS, fixed with $4 \%$ paraformaldehyde and washed with PBS. For imaging with $\lambda_{\text {exc }} 630 \mathrm{~nm}$, Olympus BX53 fluorescent microscope with X-Cite 120PC Q adapter was used. 


\section{Acknowledgements}

This work was supported by Wroclaw Research Center EIT+ under the project 'Biotechnologies and advanced medical technologies' - BioMed (POIG 01.01.02-02-003/08-00) financed from the European Regional Development Fund Operational Programme Innovative Economy 1.1.2, and was also financed by a statutory activity subsidy from the Polish Ministry of Science and Higher Education for the Faculty of Chemistry of Wrocław University of Technology.

\section{References}

1. Lü, W. Y. ; Sun, C. M.; Lu, Q.; Li, N.; Wu, D.Z.; Yao, Y. Y; Chen, W. X. Sci. China Chem. 2012, 55, 1108. http://dx.doi.org/10.1007/s11426-011-4444-2

2. Ali, H.; van Lier, J. E. Chem. Rev., 1999, 99, 2379.

http://dx.doi.org/10.1021/cr980439y

3. Tuncel, S.; Dumoulin, F.; Gailer, J.; Sooriyaarachchi, M.; Atilla, D.; Durmus, M.; Bouchu, D.; Savoie, H.; Boyled R. W.; Ahsen, V. Dalton Trans. 2011, 40.

http://dx.doi.org/10.1039/CODT01260B

4. de Oliveira, K. T.; de Assis, F. F.; Ribeiro, A. O.; Neri, C. R.; Fernandes, A. U.; Baptista, M. S.; Lopes, N. P.; Serra, O. A.; lamamoto, Y. J. Org. Chem. 2009, 74, 7962.

http://dx.doi.org/10.1021/jo901633a

5. García Vior, M. C.; Marino, J.; Roguin, L.; Sosnik, A.; Awruch, J. Photochem. Photobiol. 2013, 89, 492. http://dx.doi.org/10.1111/j.1751-1097.2012.01229.x

6. Tu, J.; Wang, T.; Shi, W.; Wu, G.; Tian, X.; Wang, Y.; Ge, D.; Ren, L. Biomaterials 2012, 33, 7903. http://dx.doi.org/10.1016/i.biomaterials.2012.07.025

7. Shaabani, A.; Safari, N.; Bazgier, A.; Bahadoran, F.; Sharifi, N.; Jamaat, P. R. Synth. Commun. $2003,33$. 1717 http://dx.doi.org/10.1081/SCC-120018933

8. Mutyala, A. K.; Park, J. S. Tetrahedron Lett. 2016, 57, 1109. http://dx.doi.org/10.1016/i.tetlet.2016.01.098

9. Sharman, W. M.; Kudrevich, S. V.; van Lier, J. E. Tetrahedron Lett. 1996, 37, 5831. http://dx.doi.org/10.1016/0040-4039(96)01243-9

10. Zorlu, Y.; Dumoulin, F.; Bouchu, D.; Ahsen, V.; Lafont, D. Tetrahedron Lett. 2010, 51, 6615. http://dx.doi.org/10.1016/i.tetlet.2010.10.044

11. Oda, K.; Ogura, S.; Okura, I. J. Photochem. Photobiol. B 2000, 59, 20. http://dx.doi.org/10.1016/S1011-1344(00)00129-9

12. Nackiewicz, J.; Kliber, M. Arkivoc 2015, (i), 269. http://dx.doi.org/10.3998/ark.5550190.p008.923

13. Bıyıklıoglu, Z.; Çakır, V.; Çakır, D.; Kantekin, H. J. Organomet. Chem. 2014, 749, 18. http://dx.doi.org/10.1016/j.jorganchem.2013.07.079

14. Bıyıklıolu, Z.; Kantekin, H. Synth. Met. 2011, 161, 943. http://dx.doi.org/10.1016/i.synthmet.2011.02.027

15. De Filippis, M.P.; Dei, D.; Fantetti, L.; Roncucci, G. Tetrahedron Lett. 2000, 41, 9143. http://dx.doi.org/10.1016/S0040-4039(00)01638-5 
16. Kuznietsova, N. A.; Gretsova, N. S.; Derkacheva, V. M.; Kaliya, O. L.; Lukyanets, E. A. J. Porphyr. Phthalocyanines 2003, 7, 147. http://dx.doi.org/10.1142/S1088424603000203

17. Karaoglan, G. K.; Gümrükçü, G.; Koca, A.; Gül, A.; Avcıata, U. Dyes Pigm. 2011, 90, 11. http://dx.doi.org/10.1016/i.dyepig.2010.10.002

18. Pavaskar, P. A.; Patil, S. S.; Furtado, I.; Salker, A. V. Med. Chem. Res. 2013, 22, 4300. http://dx.doi.org/10.1007/s00044-012-0427-x

19. Choi, J.-H.; Park, J.-S.; Kim, M.-H.; Lee, H.-Y.; Towns A. D. Color Technol. 2007, 123, 379. http://dx.doi.org/10.1111/j.1478-4408.2007.00112.x

20. Neises, B.; Steglich, W. Angew. Chem. Int. Ed. 1978, 17, 522. http://dx.doi.org/10.1002/anie.197805221

21. Szczepanowicz, K.; Bazylińska, U.; Pietkiewicz, J.; Szyk-Warszyńska, L.; Wilk, K. A.; Warszyński, P. Adv. Colloid Interface Sci. 2015, 222, 678.

http://dx.doi.org/10.1016/i.cis.2014.10.005

22. Bazylińska, U.; Zieliński, W.; Kulbacka, J.; Samoć, M.; Wilk, K. A. Colloids Surf. B 2016, 137, 121. http://dx.doi.org/10.1016/i.colsurfb.2015.06.043

23. Kulbacka, J.; Pucek, A.; Kotulska, M.; Dubińska-Magiera, M.; Rossowska, J.; Rols, M.-P.; Wilk, K. A. Bioelectrochem. 2016, 110, 19.

http://dx.doi.org/10.1016/j.bioelechem.2016.02.013

24. Lamch, L.; Kulbacka, J.; Pietkiewicz, J.; Rossowska, J.; Bieżuńska-Kusiak, K.; Choromańska, A.; Wilk, K. A. J. Photochem. Photobiol. B 2016, 160, 185.

http://dx.doi.org/10.1016/j.jphotobiol.2016.04.018

25. Bazylińska, U.; Lewińska, A.; Lamch, Ł.; Wilk K. A. Colloids Surf. A 2014, 442, 42. http://dx.doi.org/10.1016/j.colsurfa.2013.02.023

26. Niculescu-Duvaz, D; Getaz, J.; Springer, C. J. Bioconjug. Chem. 2008, 19, 973. http://dx.doi.org/10.1021/bc060242+

27. Young, J. G.; Onyebuagu, W. J. Org. Chem. 1990, 55, 2155. http://dx.doi.org/10.1021/jo00294a032

28. Lamch, L.; Bazylińska, U.; Kulbacka, J.; Pietkiewicz, J.; Bieżuńska-Kusiak, K.; Wilk, K. A. Photodiagnosis Photodyn. Ther. 2014, 11, 570. http://dx.doi.org/10.1016/j.pdpdt.2014.10.005 